\title{
The Optimal Design of Trench Field Rings for High Breakdown Voltage
}

\author{
Ey Goo Kang* , Sung Young Hong*, and Byoung Sub Ahn* \\ 5-San, Wangjang-li, Umseoung Kun, Chungcheongbuk-do, \\ *Dept. of Photovoltaic Engineering, Far East University, Korea \\ keg@kdu.ac.kr, fxcd@naver.com, annqod@nate.com
}

\section{Keywords: Power Devices, Trench Field Ring, Breakdown Voltage, Field Plate, Trench Depth}

\begin{abstract}
The trench field ring for breakdown voltage of power devices is proposed. The new ring c an improve $10 \%$ efficiency comparing with conventional field ring. Five parameters of trench field ring for design of trench field ring are analyzed and 2-D devices simulation and process simulations a re carried out. The number of field ring, juction depth, distance of field rings, trench width, doping profiled are discussed. The proposed trench field ring was better for higher voltage more than $1000 \mathrm{~V}$.
\end{abstract}

\section{Introduction}

Recently, as them and of power semiconductor has been rapidly increased from electric vehicle and power system inverter, power semiconductor with stability while maintaining high voltage resistance is being essentially requested. Various methods are used to maintain yield voltage at high voltage resistance power semiconductors of $600 \mathrm{~V}, 1200 \mathrm{~V}, 1700 \mathrm{~V}$ and $2000 \mathrm{~V}$ above. In order to disperse concentrating phenomenon of electric field at the vicinity of junction, there is the method, beside the representative method of activated junction, to use field ring which is dispersing electric field by creating junction for electric field dispersion, and there are other methods including field plate and design method of Junction Termination Edge.

In the case of the method to install field ring among these methods, main variables are repair of field ring, junction depth of field ring, and space between field rings, and optimization of these variables have nearly been accomplished. Therefore, in this study, it was intended to improve voltage characteristic through structural design of field ring, and optimization of variables in accordance with structure design was also envisaged. From this study, existing junction ring was not used and field ring with trench structure was proposed, and voltage resistance was improved through optimization of the number of field ring, depth and width of trench, and space between rings etc. in accordance with the proposal by utilizing device and process simulator.

\section{Result and review}

\subsection{Process manufacturing structure}

First of all, on account of the intention to have comparison on breakdown voltage enhancement scheme for the 4 structures of the most predominant type, i,e., field ring structure, field plate structure, trenched field ring structure, and field plate trenched field ring structure as shown in the following Fig. 1, simulation was performed by changing only the parameters related with characteristic of each structure while arranging all the other design parameters remained to be the same for all of them.

According to the simulation result, the BV turned out to be $1166 \mathrm{~V}$ for conventional field ring, 1209 $\mathrm{V}$ for Field plate, $1284 \mathrm{~V}$ for Trenched field ring, and $1298 \mathrm{~V}$ for field plate trenched field ring, respectivel y. Through this, it was confirmed that Trenched field ring structure and Field plate trenched field ring struc ture possess the best characteristics, and by comparing various characteristics of the two, the better structur e was selected.

\subsection{Disadvantage of Field plate trenched field ring}

In the case when Field plate is applied to extra high voltage power device, electric field can be concentrated to plate electrode corner as shown in the following Fig. 2, and by this, the device can be breakdown at less than estimated yield voltage. 
In addition, when electric field of more than $0.800 \mathrm{MV} / \mathrm{cm}$ is applied to silicon oxidized film, generation probability of silicon oxidized film's degradation will be increased by geometric progression, and concentration of electric field at corners of plate electrode as above generates degradation to the oxidized film below the corners, and consequently, the probability to reach thermal breakdown becomes heightened. In order to prevent this, more thick dielectric (oxidized film) is to be required between substrate and plate when the device goes up to high voltage, and this will have to be confronted with the limitation of process.

In order to manufacture the plate, dielectric etching, metallization, and metal etching process etc. mus $\mathrm{t}$ be performed, and during this process, probability to create electric charge at substrate surface and dielect ric interface becomes high.

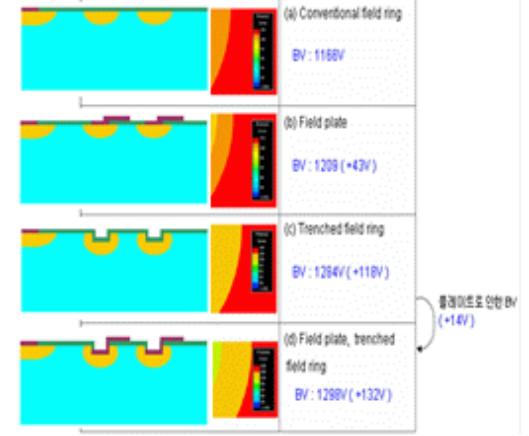

Fig. 1 Breakdown voltage characteristics of four structures

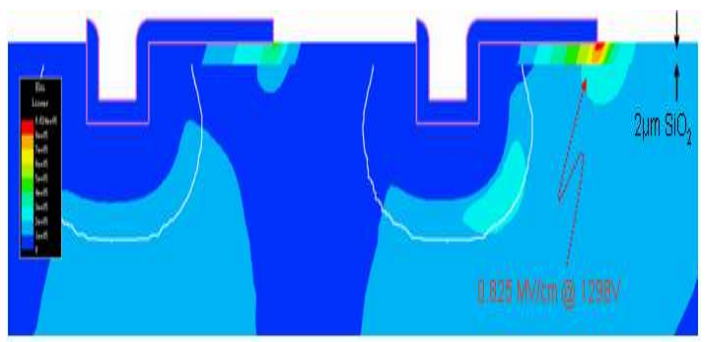

Fig. 3 Electric Field of plate edge
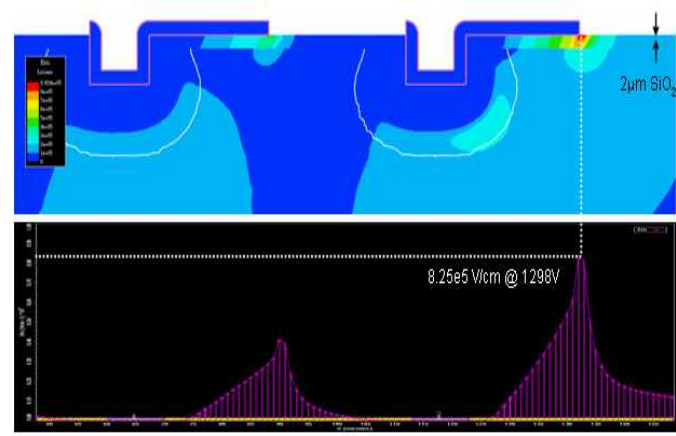

Fig. 2 Electric Field concentration of Field plate trenched field ring

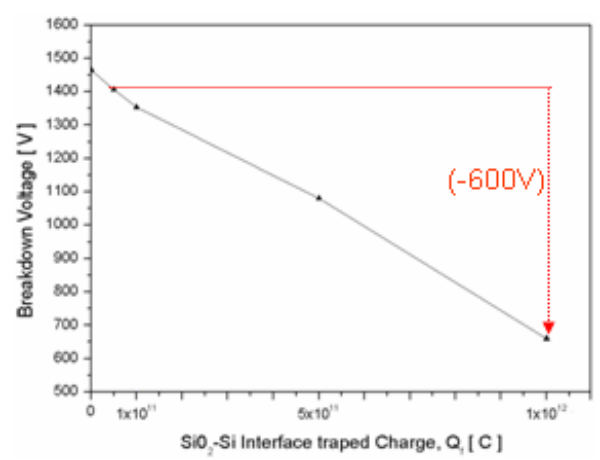

Fig. 4 Reducing breakdown voltage by interface charge

\subsection{Advantage of trenched field ring}

The largest advantage of Trenched field ring is to have sufficient junction depth. This can be confirmed from the following Fig. 5, where the junction depth has been increased approx. 20\%.

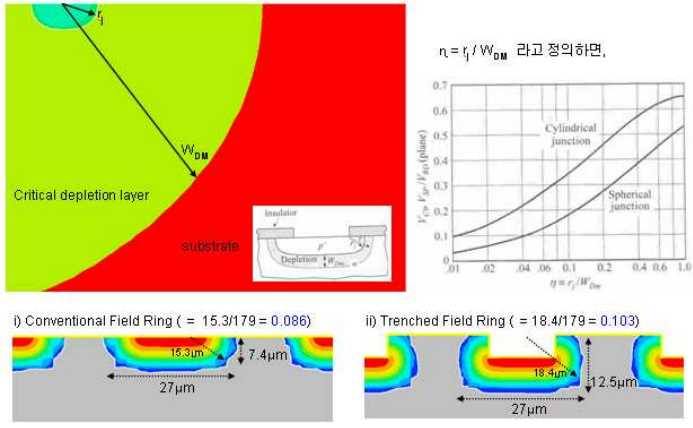

Fig. 5 Juction depth of trench field ring

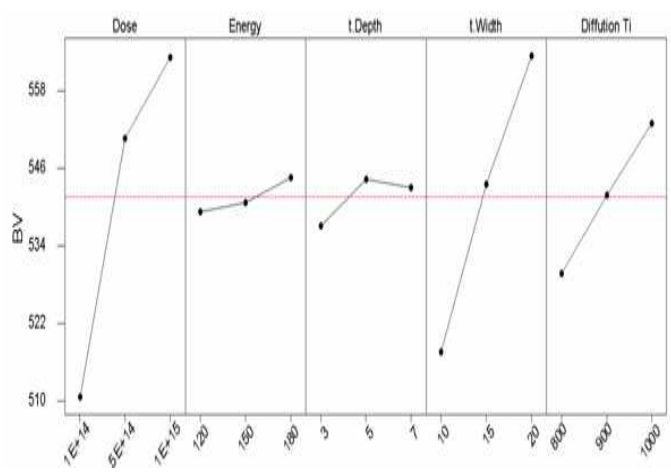

Fig. 6 Breakdown voltage variation by five parameter of trench field ring 
Generally, in the case of power semiconductor device, junction depth exerts considerably large influence to breakdown voltage. When comparing these two structures, although breakdown voltage is slightly higher in the case of field plate trenched field ring, it is recognized to be nearly minimal compared to the disadvantage and instability possessed by the structure. In addition, in the case of trenched field ring, it has been found out that breakdown will be raised by effectively lowering maximum electric field through extension of junction depth.

Variables which have influence to design of trenched field ring would be total 5 items, i.e., dose quantity, energy, trench depth, trench width, and diffusion time. Firstly, dose quantity is the variable to decide concentration of field ring, and secondly, energy is the variable to exert influence to junction depth. Thirdly, trench depth seems to exert influence to junction depth, and fourth, trench depth is the variable to exert influence to electric field distribution. Finally, diffusion time is also the variable to exert influence to junction depth. Corresponding values are to be decided through the result of total 243 times of experiments with 3 levels for the 5 variables.

Based on the analysis result of yield voltage for 35 samples through D.O.E, the following graph showing influence exerted to yield voltage by individual variable can be obtained.

First of all, as trench depth can be decided without difficulty, it is confirmed that the highest BV is occurred in the case of $5 \mu \mathrm{m}$. In addition, trench width and diffusion time have to be decided and these variables are the elements to decide BV as well as cell size. Therefore, when considering area efficiency rather than simply calculating BV only, it is concluded that to apply $15 \mu \mathrm{m}$ for width and 900 minutes for diffusion time is the most appropriate choice.

In addition, in accordance with the process conditions, remaining two variables can be decided as $5 \times$ $10^{14} \mathrm{~cm}^{2}$ for dose quantity, $150 \mathrm{KeV}$ for energy. Consequently, final values of each of the design variables can be arranged as shown in the following figure. In order to examine newly proposed enhancement point of trenched field ring, requirement of the quantity of distance for existing conventional field ring and trenc hed field ring to withstand the voltage of $1400 \mathrm{~V}, 2400 \mathrm{~V}$ was investigated through simulation. $3000 \mathrm{~V}$ tren ched field ring was designed by utilizing design variables decided above and adjusting space between field rings. The number of total field ring required at this moment was 17 units and total required area was 819 $\mu \mathrm{m}$. The space between field rings was increased gradually as $8 / 9 / 10 / 11 / 12 / 13 / 13 / 14 / 15 / 16 / 17 / 18 / 19 / 20 / 2$ $1 / 22 / 22$, and based on the result, field ring with breakdown voltage of $3005 \mathrm{~V}$ can be designed. This is the value corresponded to approx. $78 \%$ of $3830 \mathrm{~V}$ which is the breakdown voltage of parallel plan branch jun ction under the same condition in the following figure, and it can be recognized that it has the breakdown voltage with the enhancement of approx. $173 \%$ compared to $2216 \mathrm{~V}$ of conventional field ring under the s ame condition.
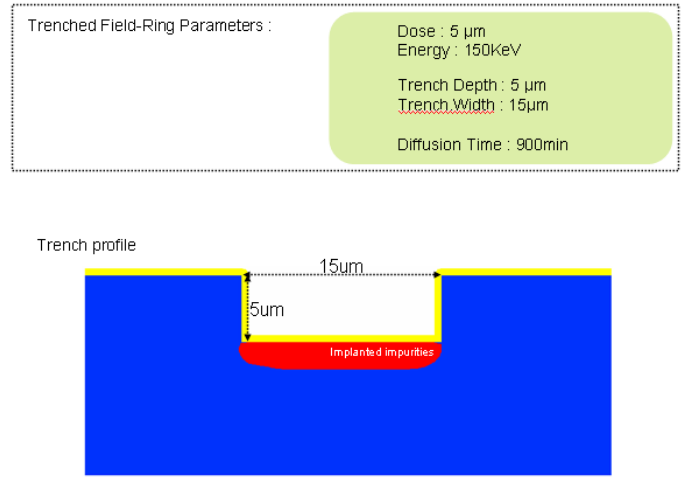

Fig. 7 Results of five parameter of trench field ring

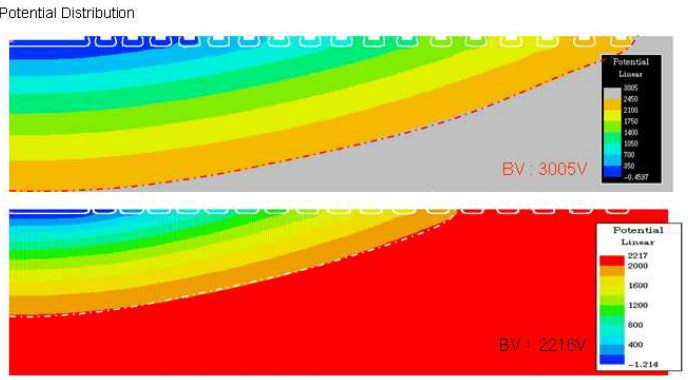

Fig. 8 Improved breakdown characteristics of trench field ring 


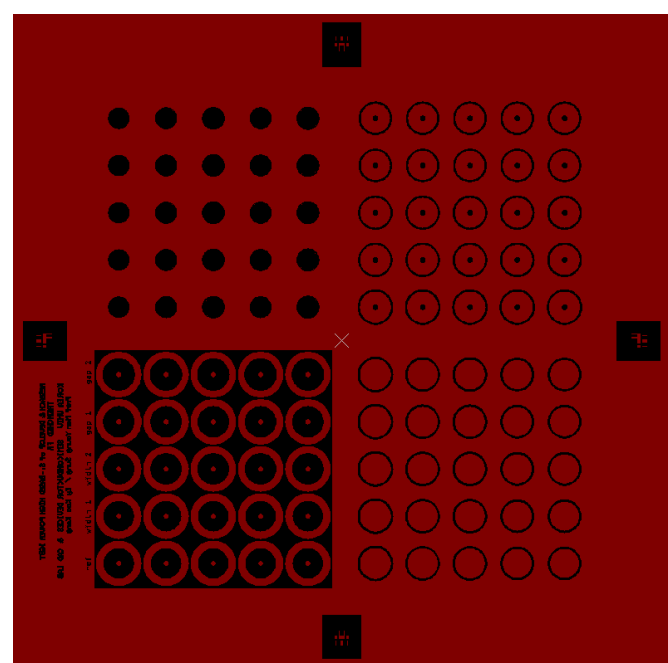

Fig. 9 Mask of trench field ring

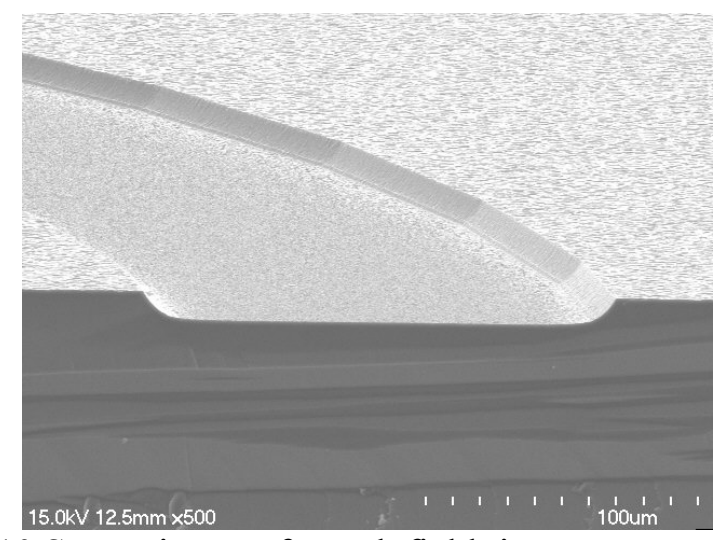

Fig. 10 SEM Picture of trench field ring

When reviewing, from the following figure, the electric distribution diagram of the trenched field ring designed above, it can be recognized that among the total 17 field rings, the highest electric field is $2.45 \times 10^{5} \mathrm{~V} / \mathrm{cm}$, the lowest electric field is $2.35 \times 10^{5} \mathrm{~V} / \mathrm{cm}$, and the difference is only $0.1 \times 10^{5} \mathrm{~V} / \mathrm{cm}$. In other words, the size of maximum electric field can be lowered through uniform and satisfactory distribution of electric filed which has been concentrated at the corners of planar junction, and in accordance with this, breakdown voltage has been improved.

Mask for manufacturing of experimental structure is shown in the Fig. 10. In the case of mask, its manufacturing efficiency has been maximized by constituting 1 Mask 4 Pattern as in the case of the 2nd year manufacturing.

\section{Conclusion}

In this paper, field ring with new structure was proposed to improve the field ring which is the most important item to maintain voltage resistance of power semiconductor. Proposed trench field ring improved more than $10 \%$ of efficiency compared to existing general field ring. Optimized simulation was performed with 5 variables for the design of trench field ring, and with the parameter result which has been achieved, manufacturing was conducted by designing the mask. The more voltage resistance is increased, better result could be brought by trench field ring than general field ring. This result is considered to be sufficiently utilized to the design of IGBT which is power semiconductor device, Power MOS, and MCT device in the future.

\section{Acknowledgement}

This study has been performed with the support of preceding power technology project (2008T100100248) and power IT project from the original technology development of power industry, Ministry of Knowledge Economy.

\section{References}

[1] E. G. Kang, M. Y. Sung, A novel lateral trench electrode IGBT for super electrical characteristics, J. KIEEME No. 15. Vol. 9, p.758, 2002

[2] K . Sheng, S.J. Finney, B.W. Williams, Improved understand- switched thyristors, in: Proceedings of the ISPSD, p. 48, 1994.

[3] S. Sridhar, B. J. Baliga, The dual gate emitter switched thyristor, IEEE EDL, No. 17, p. 25, 1996

[4] N. Iwamuro, A. Okamoto, Forward biased safe operating area of emitter switched thyristor, IEEE Trans. ED, Vol. 42, p. 334, 1995.

[5] N. Thapar, B. J. Baligar, An experimental evluation of the on-state performance of trench IGBT designs, SSE, Vol. 45, No. 5, p. 771, 1998

[6] F. Udera, S.S.M. Chan, $1.2 \mathrm{kV}$ trench insulated gate bipolar transistors with ultra low on resistance, IEEE Trans. EDL, Vol. 20, No. 8, p. 428, 1999 